\title{
Withania somnifera and its emerging anti-neoplastic effects
}

\author{
Shailendra Kapoor
}

Received: 29 September 2012/ Accepted: 29 November 2012/Published online: 8 December 2012

(C) Springer Basel 2012

\section{To the Editor,}

I read with great interest the recent article by Minhas et al. (2012). Withania may exert a number of anti-proliferative effects besides its protective role in SLE.

Withaferin A and withanolide are both extracted from Withinia. Of these, withaferin A is the most potent though withanolide also exhibits growth inhibiting activity (Choudhary et al. 2010). These anti-proliferative effects are clearly seen in NCI-H460 lung cancer cell lines (Yadav et al. 2010). Similarly, when applied to lung cancer cell lines, Withania augments the anti-neoplastic effects of chemotherapeutic agents such as paclitaxel (Senthilnathan et al. 2006). Withania extracts appear to have an immunomodulatory effect and enhance paclitaxel-induced inhibition of cell proliferation. Witharin also appears to be a radio sensitizer as it increases radio sensitivity of tumors and thereby enhances the apoptotic effects of radiotherapy (Muralikrishnan et al. 2010).

Withania extracts appear to inhibit proliferation in HCT-15 colon cancer cell lines. For instance, it attenuates azoxymethane-induced colon cancer by modulating the levels of immunoglobulins $\mathrm{G}, \mathrm{A}$, and $\mathrm{M}$ and by exerting direct anti-proliferative effects (Mathur et al. 2004).

1-oxo-5beta, 6beta-epoxy-witha-2-enolide derived from Withania root has shown efficacy in the management of ultraviolet-B-induced dermatological carcinomas (Devi et al. 1996). Withania also appears to play a role in

\footnotetext{
S. Kapoor $(\square)$

Mechanicsville, VA, USA

e-mail: shailendrakapoor@yahoo.com

S. Kapoor

74 Crossing Place, Mechanicsville, VA, USA
}

chemoprevention of skin malignancies. For instance, extracts from Withania roots have been shown to prevent the development of 7,12-dimethylbenz[a]anthracene (DMBA)induced skin cancers (Prakash et al. 2002).

The above examples clearly illustrate the anti-proliferative effects of Withania and the need for further studies in this regard.

Conflict of interest No conflicts of interest.

\section{References}

Choudhary MI, Hussain S, Yousuf S, Dar A, Mudassar, Atta-urRahman (2010) Chlorinated and diepoxy withanolides from Withania somnifera and their cytotoxic effects against human lung cancer cell line. Phytochemistry 71:2205-2209

Devi PU, Akagi K, Ostapenko V, Tanaka Y, Sugahara T (1996) Withaferin A: a new radiosensitizer from the Indian medicinal plant Withania somnifera. Int J Radiat Biol 69:193-197

Mathur S, Kaur P, Sharma M et al (2004) The treatment of skin carcinoma, induced by UV B radiation, using 1-oxo-5beta, 6beta-epoxy-witha-2-enolide, isolated from the roots of Withania somnifera, in a rat model. Phytomedicine 11:452-460

Minhas U, Minz R, Das P, Bhatnagar A (2012) Therapeutic effect of Withania somnifera on pristane-induced model of SLE. Inflammopharmacology 20:195-205

Muralikrishnan G, Dinda AK, Shakeel F (2010) Immunomodulatory effects of Withania somnifera on azoxymethane induced experimental colon cancer in mice. Immunol Invest 39:688-698

Prakash J, Gupta SK, Dinda AK (2002) Withania somnifera root extract prevents DMBA-induced squamous cell carcinoma of skin in Swiss albino mice. Nutr Cancer 42:91-97

Senthilnathan P, Padmavathi R, Banu SM, Sakthisekaran D (2006) Enhancement of antitumor effect of paclitaxel in combination with immunomodulatory Withania somnifera on benzo(a)pyrene induced experimental lung cancer. Chem Biol Interact 159:180-185

Yadav B, Bajaj A, Saxena M, Saxena AK (2010) In vitro anticancer activity of the root, stem and leaves of Withania somnifera against various human cancer cell lines. Indian J Pharm Sci 72:659-663 